\title{
Protocol
}

\section{Obtaining Xenopus laevis Eggs}

\author{
Nikko-Ideen Shaidani, Sean McNamara, ${ }^{1}$ Marcin Wlizla, and Marko E. Horb ${ }^{2}$ \\ National Xenopus Resource, Marine Biological Laboratory, Woods Hole, Massachusetts 02543, USA
}

\begin{abstract}
Nearly a century ago, studies by Lancelot Hogben and others demonstrated that ovulation in female Xenopus laevis can be induced via injection of mammalian gonadotropins into the dorsal lymph sac, allowing for egg production throughout the year independent of the normal reproductive cycles. Hormonally induced females are capable of producing thousands of eggs in a single spawning, which can then be fertilized to generate embryos or used as a substrate for generation of egg extracts. The protocol for induction of ovulation and subsequent egg collection is straightforward and robust, yet some of its details may vary among laboratories based on prior training, availability of necessary reagents, or the experimental objectives. As the goal of this protocol is not to describe every single variation possible for acquiring eggs but to provide a simple and clear description that can be easily applied by researchers with no prior working experience with $X$. laevis, we focus on describing the method we use at the National Xenopus Resource-that is, inducing ovulation in X. laevis via dorsal lymph sac injection of gonadotropic hormones and the stimulation of egg laying through application of gentle pressure to the females.
\end{abstract}

\section{MATERIALS}

It is essential that you consult the appropriate Material Safety Data Sheets and your institution's Environmental Health and Safety Office for proper handling of equipment and hazardous materials used in this protocol.

RECIPES: Please see the end of this protocol for recipes indicated by $<R>$. Additional recipes can be found online at http://cshprotocols.cshlp.org/site/recipes.

Reagents

Egg-laying solution (optional; see Steps 11-20):

Marc's modified Ringer solution $(\mathrm{MMR})<\mathrm{R}>$

Modified Barth's saline for Xenopus (MBS) $<\mathrm{R}>$

Hormone solutions for egg laying in Xenopus $<\mathrm{R}>$

Generally, pregnant mare serum gonadotropin (PMSG) is used for priming (see Steps 1-5), and either human chorionic gonadotropin (hCG) or ovine luteinizing hormone (oLH) is used for boosting (see Steps 6-10).

Xenopus laevis mature female frogs, preferably no younger than 18 mo old

Equipment

Incubator at $18^{\circ} \mathrm{C}$

Petri dish (sterile)

\footnotetext{
${ }^{1}$ Present address: Iwaki Aquatic, Holliston, Massachusetts 01746, USA

${ }^{2}$ Correspondence: mhorb@mbl.edu

From the Xenopus collection, edited by Hazel L. Sive.

(C) 2021 Cold Spring Harbor Laboratory Press

Cite this protocol as Cold Spring Harb Protoc; doi:10.1101/pdb.prot106203
} 
N.-I. Shaidani et al.

Standard X. laevis maintenance facility (see Protocol: Animal Maintenance Systems: Xenopus laevis [Shaidani et al. 2020a])

Syringes (1-mL) and needles (e.g., PrecisionGlide, $27 \mathrm{G} \times 3 / 8^{\prime \prime}$, from Becton, Dickinson and Company)

Temporary holding tank (see Step 9)

Use a plastic mouse cage or a large Tupperware container with an aerated cover that can be secured to prevent the frogs from escaping.

Transfer pipettes

\section{METHOD}

\section{Priming}

Prime frogs 1-7 d before planned ovulation. The priming injection on its own does not induce egg laying. Instead, it promotes consistent production of a high number of mature eggs following the boosting injection. The use of PMSG for priming has been shown to improve follicular maturity.

1. Remove PMSG stock from $-20^{\circ} \mathrm{C}$ freezer and allow it to thaw at room temperature or $37^{\circ} \mathrm{C}$.

2. Fill the 1-mL syringe with 30-50 U of $100 \mathrm{U} / \mathrm{mL}$ PMSG.

Smaller inbred J-strain frogs require less hormone and can be primed with $30 \mathrm{U}$ of PMSG, whereas larger wild-type frogs can be given $50 \mathrm{U}$ of PMSG.

Alternatively, hCG can be used to prime females at 0.1 of the amount used for boosting or $50 \cup$ for a wildtype female.

3. Pick up and restrain the female with one hand in such a way that the dorsal surface of the frog is rested against palm of the hand with the head of the frog pointed toward the wrist (Fig. 1A,B). Place the thumb and the middle finger along the posterior sides of the animal abdomen and use the index finger to abduct one of the frog's hind limbs (Fig. 1C).

If possible, the palm of the hand should cover the frog's eyes, which will help keep it calm. This hold makes the dorsal lymph sac pocket easily accessible while restraining the animal.

4. With the other hand, insert the needle subcutaneously through the dorsal surface into the dorsal lymph sac in the posterior medial region of the animal proximal to the lateral line "stitch marks" and slowly inject the hormone (Fig. 1C-E).

Insert the needle at a shallow angle to prevent penetrating muscle.

5. Return the frog to its permanent tank and do not feed until after the eggs have been collected.

Adult frogs can regurgitate food following hormone injection, and the presence of solid waste can reduce the durability of the laid eggs.

\section{Boosting}

Perform the boosting injection the evening before egg collection (see Step 10 for timing details). The boosting injection promotes the final steps of oocyte maturation and is necessary for induction of ovulation. Females given a boosting injection are likely to spawn, even if they have not been given a prior priming injection. The priming injection serves to ensure consistent egg-laying response to the boosting injection.

6. Remove oLH or hCG stock from $-20^{\circ} \mathrm{C}$ freezer and allow it to thaw at room temperature or $37^{\circ} \mathrm{C}$.

7. Fill a 1 -mL syringe with $2 \mu \mathrm{g}$ of oLH per $1 \mathrm{~g}$ of body mass (typically $\sim 200 \mu \mathrm{g}$ of $0.4 \mathrm{mg} / \mathrm{mL} \mathrm{oLH}$ ) or with $500 \mathrm{U}$ of $1000 \mathrm{U} / \mathrm{mL}$ hCG.

Smaller inbred J-strain females require less hormone and can be primed with $120 \mu \mathrm{g}$ of oLH or $300 \mathrm{U}$ of hCG. Larger wild-type females require $200 \mu \mathrm{g}$ of oLH or $500 \mathrm{U}$ of hCG.

8. Inject the frog as described in Steps 3 and 4.

9. Prepare a temporary holding tank with system water for the frog. 

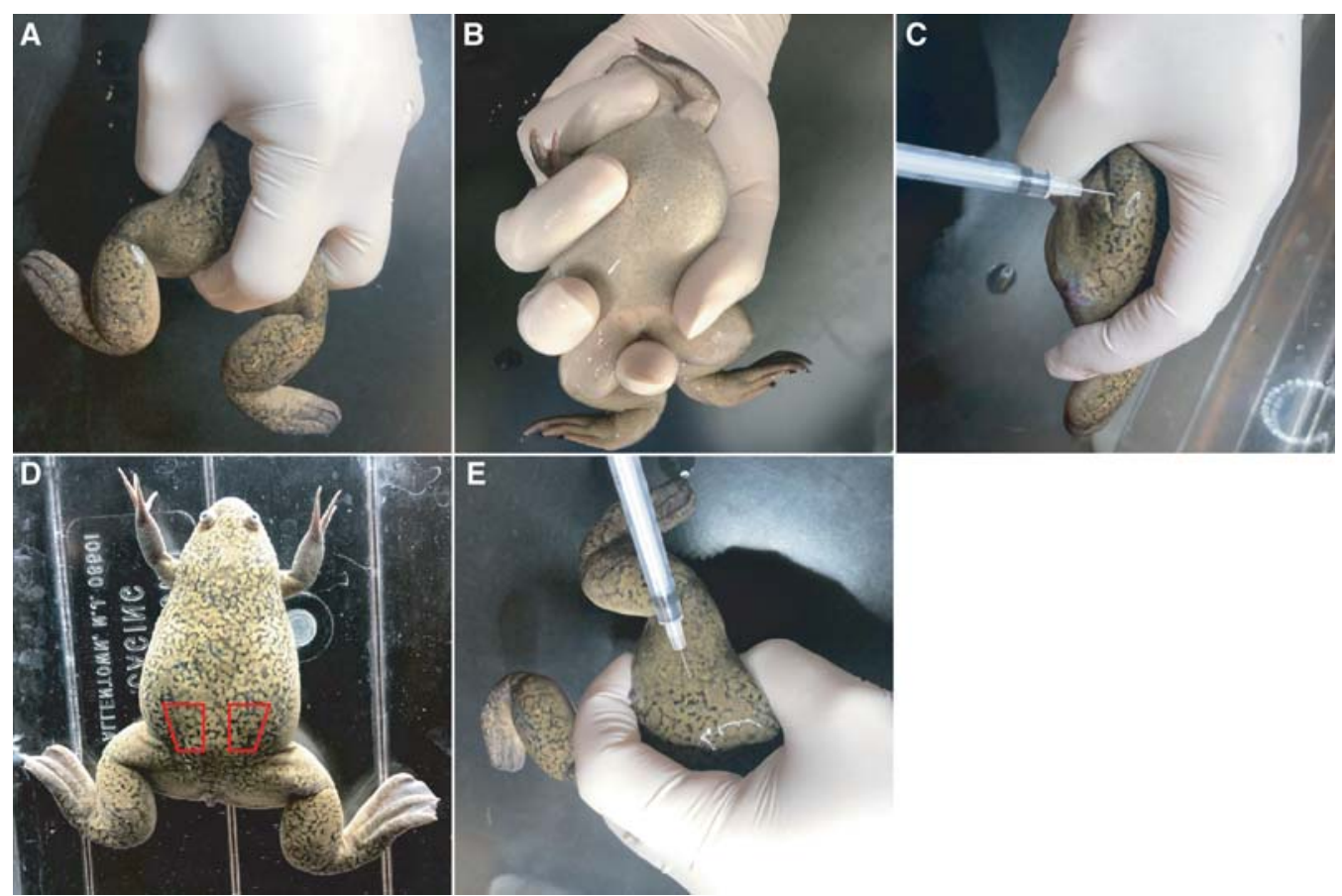

FIGURE 1. Single hand manual frog restraint for gonadotropin injection and egg collection. $(A)$ View from the dorsal surface with the index finger in-between both legs, one of the legs being held between the index and the middle fingers, the thumb located around the waist on the other side of the frog. $(B)$ View of the hold from the ventral surface with the index finger between the legs, the middle finger and the thumb located on the waist on the opposite sides of the frog, and the tip of the little finger pressed against the throat to secure the head against the base of the palm of the hand, thus aiding to cover the eyes. $(C)$ The frog in fully restrained hold with one of the legs pulled back against the abdomen and a needle ready for injection through the dorsal surface. $(D) X$. laevis female adult with the general location of the dorsal posterior lymph sacs, the injection target, outlined in red. $(E)$ A more relaxed hold on the female with neither leg fully restrained against the abdomen and with a needle ready for injection through the dorsal surface.

10. Place the frog in the holding tank, and place the tank into an $18^{\circ} \mathrm{C}$ incubator.

Ovulation will begin $\sim 8-12 \mathrm{~h}$ postinjection and should continue for $\sim 5 \mathrm{~h}$. Do not feed the frogs while waiting for them to lay eggs.

The onset of ovulation can be delayed by several hours by keeping the female at a lower temperature of $15^{\circ} \mathrm{C}$.

\section{Obtaining Eggs}

11. Remove the temporary holding tank with the frog from the $18^{\circ} \mathrm{C}$ incubator.

The steps below describe a way of handling a female frog to promote egg laying and subsequent collection of a batch of eggs into a Petri dish. As an alternative, at this point the system water in the frog holding tank can be replaced with an egg-laying solution like $1 \times M M R$ or $1 \times M B S$. The viability of eggs laid into system water is lost rapidly but can be maintained for at least $1 \mathrm{~h}$ if laid into egg-laying solution. This allows for eggs to be collected throughout the day, without the need to handle the females. The animals tolerate being placed in the egg-laying solution well; however, further handling to promote egg laying should be avoided as it does stress the females. This approach is potentially less reliable at producing a large number of viable eggs at exactly the desired time.

12. Obtain a sterile Petri dish for egg collection.

13. Similar to the hold used for restraining the animal during hormone injection, gently but firmly pick up the female from the dorsal side with the dominant hand, allowing its head to be concealed by the palm (Fig. 1A,B).

The frog should be in the prone position. 
N.-I. Shaidani et al.

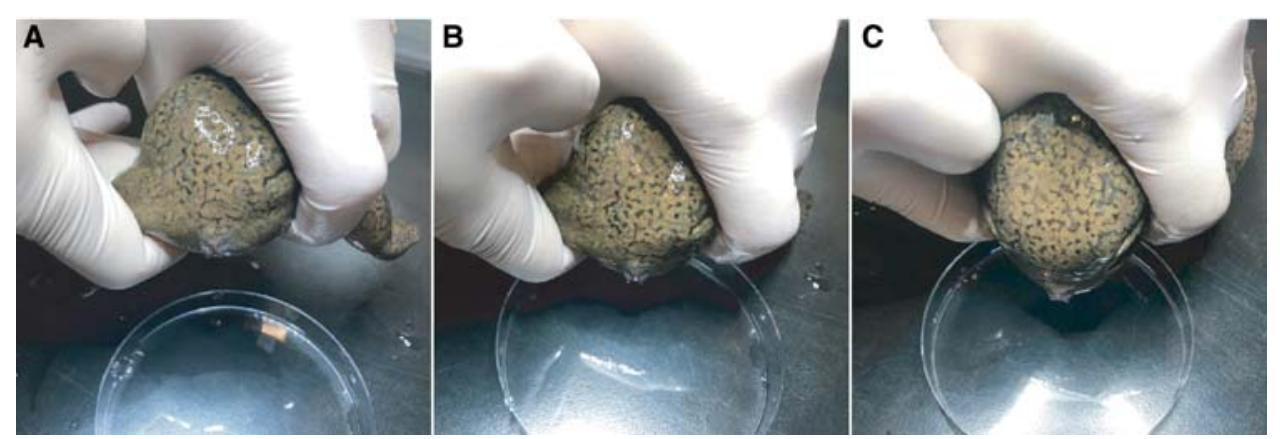

FIGURE 2. Manual two-handed restraint of a female ready for egg expulsion. (A) Initial hold with the female held in the dominant hand. The face of the frog rests against the inside of the base of the palm of the hand. One of the legs is held between the index and the middle finger while the thumb is near the pit of the contralateral arm. The other leg is being restrained between the index and the middle fingers of the other hand. $(B)$ Both hands are used to progressively pull both legs out and forward toward the head. $(C)$ Fully restrained female with both legs held against the abdomen. The hold is loose enough to allow the female to wiggle and flex its leg and abdominal muscles, yet firm enough to prevent it from breaking loose.

14. Place the thumb and middle finger along the posterior side of the female with the little finger against the throat of the animal to restrain it further.

15. Using the index finger, abduct one of the frog's hind limbs to reflect it rostralward. At the same time abduct the second limb using the other hand (Fig. 2A-C).

This will expose the cloaca/vent and allow for the best control when attempting to position the female. The thumb, ring, and index finger should be available to massage the dorsal and ventral lower trunk.

16. Position the female vertically, with the cloaca over the Petri dish.

This helps prevent the eggs from running along the body of the female.

17. Use the dominant hand's ring and middle finger tips to apply pressure to the belly and the other hand's thumb to apply pressure to the back of the animal.

18. Gently shift the pressure in an anterior to posterior direction to aid the expulsion of eggs.

Simply restraining the female in the described hold, without applying additional pressure, is often sufficient for egg expulsion. The hold itself should be tight and stiff enough to prevent the female from breaking loose. Eggs will come out as she flexes her leg and abdominal muscles attempting to escape. If no eggs come out when simply holding the animal, gently increase the applied pressure being sure not to hurt the animal. Monitor the animal for stress indicators such as sudden excess of skin surface mucus. Females should only be squeezed once every hour and no more than three times in a single day.

19. Transfer the frog to a clean tank overnight and allow it $24 \mathrm{~h}$ to recover prior to returning it to the system.

When dealing with albino females in particular, even gentle pressure may result in mild bruising around the eyes and the part of the abdomen handled directly. This bruising will disappear within hours and has no long-term ill effects on the health of the female. X. laevis are hardy, although care should be taken not to apply such pressure that it leads to injury.

20. Immediately after putting the female back, use a transfer pipette to remove any system water that may have dripped into the egg dish during collection.

Egg viability will decline rapidly if eggs are exposed to a significant amount of system water. If collected eggs are not going to be used immediately, it may be useful to flood the egg collection dish with $1 \times$ MMR or 1x $M B S$, which will prevent them from drying out and will help maintain their viability for at least an hour.

The method described here is well-established (Wlizla et al. 2017, 2018) and allows for a simple and efficient way to collect eggs from female X. laevis at desired times. These eggs can then be used directly 
in experiments or fertilized via in vitro fertilization (IVF) to generate embryos (see Protocol: Obtaining Xenopus laevis Embryos [Shaidani et al. 2020b]). Developing a correct technique for restraining $X$. laevis females for hormone injection and egg collection requires some practice but is essential for decreasing distress caused to the animal and for collecting the best-quality eggs. Restrained frogs appear to struggle less against the hold when their eyes are covered. For those not experienced in holding frogs, a good initial practice may be to place a moist paper towel on a tabletop, put the female on the paper towel, and gently wrap her head to cover her eyes while keeping the posterior dorsal surface still accessible for injection. This way the hard tabletop surface can be used to aid in immobilizing the animal.

Another aspect of this procedure that requires some practice is determining the amount of pressure that should be applied to the animal during egg expulsion. Too little pressure might not produce any eggs, whereas too much may cause the eggs to be damaged or cause injury to the animal. If simply holding the female is not productive, some pressure will be necessary. The pressure should be applied in a way in which it shifts in a rostral to caudal direction so that it is not simply a squeeze, but instead a massage intended to push the eggs toward and out of the cloaca. As an alternative to handling the female, following the boosting hormone injection, she can be placed in a tank containing egglaying solution. The female will lay eggs at a slower rate but they will maintain their viability for at least $1 \mathrm{~h}$ and can be collected directly from the tank; however, it is likely that the total amount of eggs produced will not be as high without the additional manual pressure. Common egg-laying solutions include $1 \times$ MMR or $1 \times$ MBS, both of which work equally well for maintaining egg viability. The choice of egg-laying solution will depend on prior user experience and experimental design aspects beyond the scope of this protocol.

A final point to address is the use of mammalian gonadotropic hormone injection into the dorsal lymph sac of the $X$. laevis female as a reliable and effective way for induction of ovulation. hCG has been historically used for this purpose; however, during a shortage of commercially available hCG, we determined that other gonadotropins, including PMSG for priming and oLH or human luteinizing hormone for boosting, can stimulate spawning as effectively (Wlizla et al. 2017). Although using hormones not sourced in animals may be the more humane option when considering animal welfare, the awareness of these alternatives is useful when dealing with supply disruptions or when trying to find the most economical option.

Hormone Solutions for Egg Laying in Xenopus

Hormone Concentration in $1 \times$ PBS

Human chorionic gonadotropin (hCG; from $1000 \mathrm{U} / \mathrm{mL}$

National Hormone and Peptide Program, Sigma-Aldrich, Merck Animal Health

[Chorulon brand], or BioVendor)

Ovine luteinizing hormone (oLH; from National

Hormone and Peptide Program)

Pregnant mare serum gonadotropin (PMSG; $\quad 100 \mathrm{U} / \mathrm{mL}$ from BioVendor)

Dissolve phosphate-buffered saline (PBS) tablets (Sigma-Aldrich P4417) in type 1 ultrapure water, at a concentration of 1 tablet per $200 \mathrm{~mL}$. Sterilize by autoclaving. Prepare individual hormone solutions in $1 \times$ PBS at the concentrations listed above. Store all hormone solutions at $20^{\circ} \mathrm{C}$ until needed for use. 
N.-I. Shaidani et al.

Marc's Modified Ringer Solution (MMR)

$1 \mathrm{M} \mathrm{NaCl}$

$20 \mathrm{~mm} \mathrm{KCl}$

$10 \mathrm{mM} \mathrm{MgSO} 4 \cdot 7 \mathrm{H}_{2} \mathrm{O}$

$20 \mathrm{mM} \mathrm{CaCl}_{2} \cdot 2 \mathrm{H}_{2} \mathrm{O}$

$50 \mathrm{~mm}$ HEPES free acid

Prepare a $10 \times$ stock that consists of the reagents listed above, adjusting the $\mathrm{pH}$ to $7.4-7.8$ with $\mathrm{NaOH}$ and sterilizing by autoclaving. Store the stocks indefinitely at room temperature. Dilute stock as necessary with type 1 ultrapure water (ASTM International 2018) without further $\mathrm{pH}$ adjustment.

Modified Barth's Saline for Xenopus (MBS)

Make a $10 \times$ MBS stock:

$800 \mathrm{~mm} \mathrm{NaCl}$

$10 \mathrm{~mm} \mathrm{KCl}$

$10 \mathrm{mM} \mathrm{MgSO}_{4} \cdot 7 \mathrm{H}_{2} \mathrm{O}$

$50 \mathrm{~mm}$ HEPES free acid

$25 \mathrm{~mm} \mathrm{NaHCO}_{3}$

Prepare a $10 \times$ stock that consists of the reagents listed above, adjusting the $\mathrm{pH}$ to 7.8 with $\mathrm{NaOH}$ and sterilizing by autoclaving. Prepare a separate $0.1 \mathrm{M}$ stock of $\mathrm{CaCl}_{2}$, and sterilize by autoclaving. Store the stocks indefinitely at room temperature.

To make $1 \times$ MBS, dilute the $10 \times$ MBS stock with type 1 ultrapure water (ASTM International 2018), and add $\mathrm{CaCl}_{2}$ stock to a final concentration of $0.7 \mathrm{~mm}$.

\section{REFERENCES}

ASTM International. 2018. ASTM standard D1193-06 (2018). "Standard specification for reagent water." ASTM, West Conshohocken, PA.

Shaidani N-I, McNamara S, Wlizla M, Horb ME. 2020a. Animal maintenance systems: Xenopus laevis. Cold Spring Harb Protoc doi:10.1101/pdb prot 106138

Shaidani N-I, McNamara S, Wlizla M, Horb ME. 2020b. Obtaining Xenopus laevis embryos. Cold Spring Harb Protoc doi:10.1101/pdb.prot106211
Wlizla M, Falco R, Peshkin L, Parlow AF, Horb ME. 2017. Luteinizing hormone is an effective replacement for hCG to induce ovulation in Xenopus. Dev Biol 426: 442-448. doi:10.1016/j.ydbio.2016.05.028

Wlizla M, McNamara S, Horb ME. 2018. Generation and care of Xenopus laevis and Xenopus tropicalis embryos. Methods Mol Biol 1865: 19-32. doi:10.1007/978-1-4939-8784-9_2 


\section{Obtaining Xenopus laevis Eggs}

Nikko-Ideen Shaidani, Sean McNamara, Marcin Wlizla and Marko E. Horb

Cold Spring Harb Protoc; doi: 10.1101/pdb.prot106203 originally published online December 3, 2020

\begin{tabular}{rc}
$\begin{array}{r}\text { Email Alerting } \\
\text { Service }\end{array}$ & Receive free email alerts when new articles cite this article - click here. \\
\hline $\begin{array}{r}\text { Subject } \\
\text { Categories }\end{array}$ & $\begin{array}{c}\text { Browse articles on similar topics from Cold Spring Harbor Protocols. } \\
\text { Developmental Biology (728 articles) } \\
\text { Laboratory Organisms, general (924 articles) } \\
\text { Xenopus (210 articles) }\end{array}$ \\
\hline
\end{tabular}

